$\mathbb{P}$ periodica polytechnica

Chemical Engineering

57/1-2 (2013) $11+14$

doi: $10.3311 /$ PPch.2164

http://periodicapolytechnica.org/ch

Creative Commons Attribution (i)

RESEARCH ARTICLE

\section{Investigation of $\mathrm{Mg} / \mathrm{Al}$ alloy sacrificial anode corrosion with Scanning Electrochemical Microscopy}

\author{
András Kiss / Ricardo M. Souto / Géza Nagy
}

Received 2012-10-09, accepted 2013-02-15

\section{Abstract}

Corrosion of $\mathrm{Mg} / \mathrm{Al}$ alloy was investigated with the scanning electrochemical microscope (SECM) using a $\mathrm{Mg}^{2+}$ ion selective microelectrode (ISME) as measuring tip. $\mathrm{Mg} / \mathrm{Al}$ alloys have practical application as sacrificial anodes to prevent the corrosion of various metals susceptible to corrosion. A typical application of such sacrificial anodes is in water boilers. A model $(\mathrm{Mg} / \mathrm{Al}) / \mathrm{Fe}$ target was fabricated using boiler sacrificial anode and high purity iron wires. Corrosion current was measured between the electrically connected galvanic pair, and $\mathrm{Mg}^{2+}$ ion flow rate was calculated with Faraday's law of electrolysis. However, $\mathrm{Mg}^{2+}$ flow rate could not be calculated with this method while the twometals were left electrically-disconnected. For this reason, fixed height lateral scans and retreating scans were performed above the $\mathrm{Mg}^{2+}$ sample with $\mathrm{Mg}^{2+}$ ion-selective electrodes employed as SECM tips. $\mathrm{Mg}^{2+}$ flow rate was estimated using the concentration profiles obtained with SECM. Relatively high-speed scans were possible with robust, solid contact $\mathrm{Mg}^{2+}$ micropipette electrodes, owing to their low resistance compared to conventional micropipettes of the same size.

\section{Keywords}

Scanning Electrochemical Microscope · SECM · ion-selective microelectrode $\cdot I S M E \cdot$ galvanic corrosion $\cdot$ potentiometric tip . solid contact

\section{Acknowledgement}

This work was presented at the Conference of Chemical Engineering, Veszprém, 2012.

\section{András Kiss}

University of Pécs, Faculty of Science, Institute of Chemistry, Department of General and Physical Chemistry, Ifjúság útja 6., H-7622 Pécs, Hungary

e-mail: akiss@gamma.ttk.pte.hu

\section{Ricardo M. Souto}

University of La Laguna, Department of Physical Chemistry, E-38200 La Laguna, Tenerife, Canary Islands, Spain

\section{Géza Nagy}

University of Pécs, Faculty of Science, Institute of Chemistry, Department of General and Physical Chemistry, Ifjúság útja 6., H-7622 Pécs, Hungary

\section{Introduction}

As it is well known, by electrically connecting two metals with different redox character, a galvanic pair is formed. The more reactive metal has a lower redox potential than the other one. The galvanic connection can provide cathodic protection against corrosion of the less reactive metal. When the two are coupled, electrochemical oxidation takes place at the more reactive metal surface, while at the less reactive one, reduction proceeds - most often of oxygen. The more reactive metal gets dissolved, preventing the corrosion of the other. Because of this property, such protective metals are called sacrificial anodes or active anodes. The protection persists until the entire sacrificial anode is dissolved, then the less reactive metal starts to develop anodic sites as well, and starts to corrode. Because magnesium is among the most often used sacrificial anodes, and iron has a widespread use, it was worth to investigate the galvanic corrosion of this galvanic pair. Scanning Electrochemical Microscopy (SECM) is a relatively new, powerful technique, recently started to be applied in corrosion science [1,2]. Because corrosion processes of metals involve the formation of metal ions, SECM technique with ion-selective microelectrode (ISME) measuring tips provides a method in corrosion sciences. Corrosion of a $(\mathrm{Mg} / \mathrm{Al}) / \mathrm{Fe}$ model galvanic pair target was studied. The $\mathrm{Mg} / \mathrm{Al}$ sample was made from an actual sacrificial anode used in water boilers.

\section{Experimental}

\section{Fabrication of $\mathrm{Mg}^{2+}$ ISME electrodes}

Fabrication of solid contact electrodes has been described elsewhere [3, 4], thus only a short description will be given here. Borosilicate micropipettes were pulled using micropipette puller (Sutter Instruments Co., Novato, USA, Model: P-30). Micropipettes were cleaned with pyranha solution $(50 \% / 50 \%$ volume mixture of hydrogen-peroxide and sulfuric acid), rinsed with distilled water, then silanized with dimethyldichlorosilane solution (Fluka, Silanization Solution 1) in a Petri dish. $100 \mu \mathrm{l}$ of the silanization solution was added, and the lid of the dish was immediately closed, the pipettes were baked at $150{ }^{\circ} \mathrm{C}$ for 20 minutes. After silanization, the micropipettes were front- 


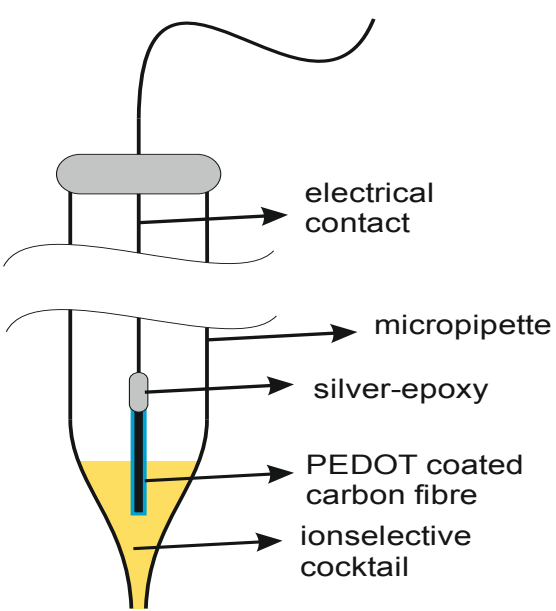

Fig. 1. Schematic design of the $\mathrm{Mg}^{2+}$ ISME used as measuring tip in the experiments.

filled with ion-selective cocktail with vacuum applied on the back of the pipette. The cocktail was prepared using bis$\mathrm{N}, \mathrm{N}$ '-dicyclohexyl-malonamide as $\mathrm{Mg}^{2+}$ ionophore, potassium tetrakis(4-chlorophenyl)borate (KTCPB), 2-nitrophenyl octhyl ether (NPOE) and polyvinyl chloride (PVC) in tetrahydrofurane (THF). The composition of the mixture was: $57.7 \mathrm{wt} . \%$ NPOE, $3.6 \%$ wt. $\% \mathrm{Mg}^{2+}$ ionophore, 3.4 wt. \% PVC, 1.3 wt.\% KTCPB, and $34.0 \mathrm{wt} . \%$ THF. The resulting membrane was let to dry for 24 hours before the immersion of the carbon fiber as internal solid contact. $33 \mu \mathrm{m}$ diameter carbon fibers (obtained as a generous gift from Specialty Materials, Lowell, Massachusetts, USA) were coated with Poly(3,4-ethylenedioxythiophene) (PEDOT) conducting polymer. PEDOT coating was prepared in EDOT polymerizing solution, the solvent was 1-butyl-3methylimidazolium hexafluorophosphate $\left(\mathrm{BMIMPF}_{6}\right)$ ionic liquid. A copper wire was glued to the rear end of the carbon fiber with silver-epoxy to provide electrical contact. Electrodes were calibrated in a $\mathrm{MgCl}_{2}$ dilution series ranging from $10^{-6} \mathrm{M}$ to $10^{-2} \mathrm{M}$. After calibration, the electrodes were stored dry until measurement, and were conditioned in $10^{-2} \mathrm{MgCl}_{2}$ solution for 2 hours before measurements. Fig. 1. shows the schematic design of the $\mathrm{Mg}^{2+}$ ISME electrode.

\section{(Mg/Al)/Fe target}

$(\mathrm{Mg} / \mathrm{Al}) / \mathrm{Fe}$ galvanic couple target was prepared from 70/30 $\mathrm{Mg} / \mathrm{Al}$ alloy (boiler sacrificial anode), and high purity Fe wires. The diameter was $0.67 \mathrm{~mm}$ for both metal samples. They were mounted in an epoxy resin sleeve, exposing only the disc shaped surfaces. Electrical contact was provided at the rear end of the mould. Frontal surface of the mould was first polished with sandpaper, then with 1.0, 0.3, and $0.03 \mu \mathrm{m}$ alumina powder.

\section{Potentiometric SECM}

Fixed height lateral scans and retracting scans were performed above the $\mathrm{Mg}$ sample, using $\mathrm{Mg}^{2+}$ ISME electrode as measuring tip, and $\mathrm{Ag} / \mathrm{AgCl} / 3.5 \mathrm{M} \mathrm{KCl}$ reference with a homemade SECM [5]. Height of lateral scans was $100 \mu \mathrm{m}$, resolution

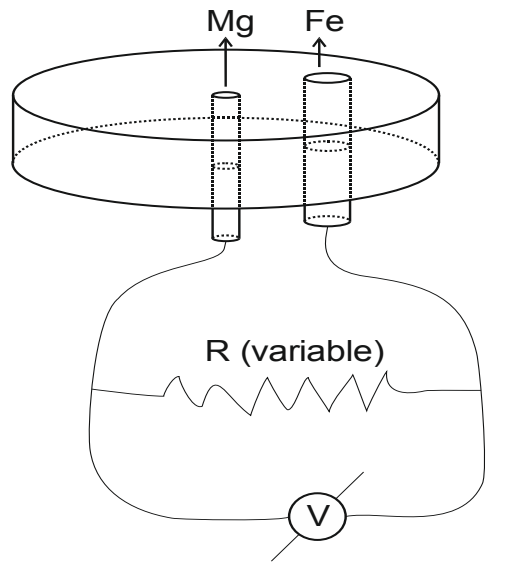

Fig. 2. $\mathrm{Mg} / \mathrm{Al}-\mathrm{Fe}$ model target in epoxy sleeve. Figure also shows the variable resistor used for estimation of the corrosion current flow between the two metals.

was $5 \mu \mathrm{m}$, lateral distance was $5 \mathrm{~mm}$ with the $\mathrm{Mg} / \mathrm{Al}$ sample in the centre. Retracting curves were recorded at $t=10,20$, $30,40,50,60$ minutes after introduction of the corrosive media, resolution was $5 \mu \mathrm{m}$. Since ion-selective electrodes of this size have high resistance compared to the low input resistance of potentiometers, to avoid loading the potentiometric sensor, a home-made high impedance voltage follower circuit was used as current buffer based on the TL082 operational amplifier (Texas Instruments, Dallas, USA). The potential was measured with a MeTeX potentiometer (MeTeX M-3630D) connected to a PC, the signal was recorded with the software provided by MeTeX. Scans were performed with the two metals either electrically connected or disconnected. Corrosive medium was distilled water saturated with air.

\section{Corrosion current}

Corrosion current cannot be measured directly, since the measurement itself would alter the current flow. However, it is possible to calculate it by measuring the voltage drop on the two sides of a variable resistor, which connects the $\mathrm{Mg}$ and Fe samples together. Plotting the voltage over the resistance $(\mathrm{E} / \mathrm{R})$ with respect to resistance, the ,y" interception will be $1 / i$ at $R=0$, after taking the reciprocal, corrosion current is obtained. Using Faraday's law of electrolysis, $\mathrm{Mg}^{2+}$ ion flow rate from the $\mathrm{Mg} / \mathrm{Al}$ sample was determined.

\section{Results}

\section{$\mathrm{Mg}^{2+}$ ISME electrodes}

$\mathrm{Mg}^{2+}$ ion selective microelectrodes were calibrated in $\mathrm{MgCl}_{2}$ solutions with concentrations from $10^{-6} \mathrm{M}$ to $10^{-2} \mathrm{M}$. Reference was $\mathrm{Ag} / \mathrm{AgCl} / 3.5 \mathrm{M} \mathrm{KCl}$. Sensitivity was $26 \mathrm{mV} /$ decade of $\left[\mathrm{Mg}^{2+}\right]$ (Fig. 3).

\section{SECM scans}

$\mathrm{Mg}^{2+}$ ion concentration profiles above the $\mathrm{Mg}$ sample were recorded by SECM scans. Vertical $\mathrm{Mg}^{2+}$ ion concentration distribution was determined at different instants in time of the cor- 


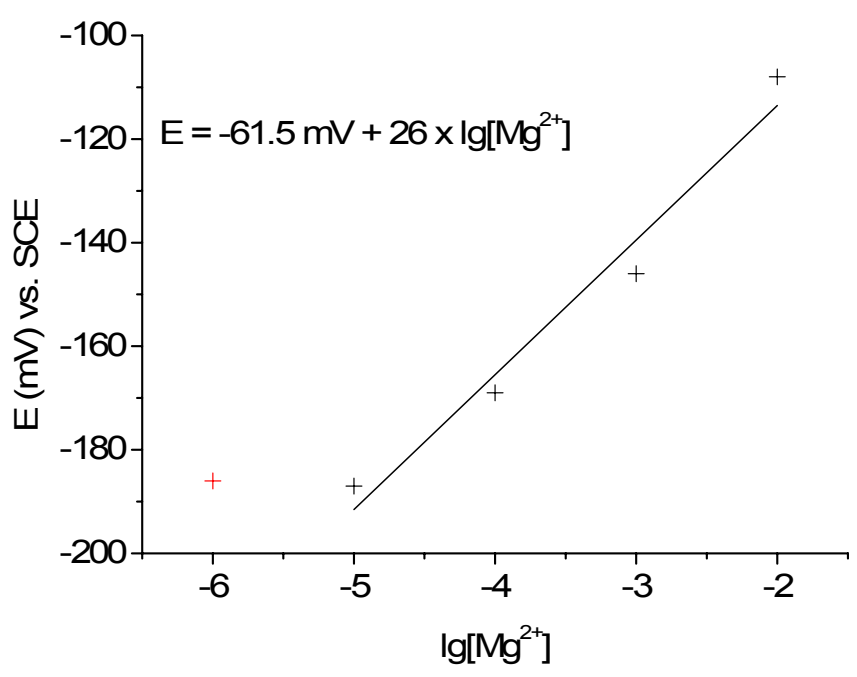

Fig. 3. Calibration plot of the $\mathrm{Mg}^{2+}$ ISME. Slope is $26 \mathrm{mV} /$ decade of $\left[\mathrm{Mg}^{2+}\right]$.

rosion process, with, and without coupling the $\mathrm{Mg} / \mathrm{Al}$ and $\mathrm{Fe}$ samples. About ten times more $\mathrm{Mg}^{2+}$ is being formed with coupling. $\mathrm{Mg}^{2+}$ concentration was increasing with time above the sample while coupled, on the other hand, it was decreasing after 10 minutes when disconnected (Fig. 4). Based on the method of Scott and White [6], using the $\mathrm{Mg}^{2+}$ concentration profiles, $\mathrm{Mg}^{2+}$ flow rate from the $\mathrm{Mg} 00 v$ piece was possible to estimate:

$$
\Omega=4 D C_{s} a
$$

where $\Omega$ is the amount of $\mathrm{Mg}^{2+}$ released from the disc shaped $\mathrm{Mg} / \mathrm{Al}$ surface in every second, $D$ is the diffusion coefficient of $\mathrm{Mg}^{2+}, C_{s}$ is the surface concentration of $\mathrm{Mg}^{2+}$ (at the height $z=0 \mu \mathrm{m}), a$ is the radius of the $\mathrm{Mg} / \mathrm{Al}$ sample. As the only unknown variable in the equation above, $\Omega$ could be calculated. Substituting the value of $D=7.06 \times$ $10^{-8} \mathrm{dm}^{2} \mathrm{~s}^{-1}$ [7], $C_{s}=3.29 \times 10^{-2} \mathrm{M}, a=0.0038 \mathrm{dm}$, the result is $\Omega=3.53 \times 10^{-11} \mathrm{~mol} / \mathrm{s}$.

\section{Corrosion current}

Corrosion current between the $\mathrm{Mg} / \mathrm{Al}$ sample and four $\mathrm{Fe}$ samples with different diameters was determined. As expected, current gets higher with increasing diameter. Corrosion current was $8.87 \mu \mathrm{A}, 15.83 \mu \mathrm{A}, 16.72 \mu \mathrm{A}, 24.4 \mu \mathrm{A}$ with Fe sample diameters of $0.59 \mathrm{~mm}, 0.76 \mathrm{~mm}, 1.2 \mathrm{~mm}$, $2.3 \mathrm{~mm}$, respectively (Fig. 6.). Using Faraday's law of electrolysis, this means, that $8.20 \times 10^{-11} \mathrm{~mol} \mathrm{Mg}^{2+}$ is being dissolved in every second from the $\mathrm{Mg} / \mathrm{Al}$ sample $\left(\Omega_{0.76 \mathrm{~mm}}=\right.$ $\left.8.20 \times 10^{-11} \mathrm{~mol} / \mathrm{s}\right)$. This result is in fairly good agreement with the result calculated from the SECM retracting curves $(\Omega=$ $3.53 \times 10^{-11} \mathrm{~mol} / \mathrm{s}$ ). Ion flow rates from $\mathrm{Mg} / \mathrm{Al}$ samples coupled with $\mathrm{Fe}$ samples of different diameters are proportional with the surface area of the sample; $\Omega_{0.59 \mathrm{~mm}}=4.60 \times 10^{-11} \mathrm{~mol} / \mathrm{s}$, $\Omega_{1.2 \mathrm{~mm}}=4.66 \times 10^{-11} \mathrm{~mol} / \mathrm{s}, \Omega_{2.3 \mathrm{~mm}}=1.26 \times 10^{-10} \mathrm{~mol} / \mathrm{s}$.

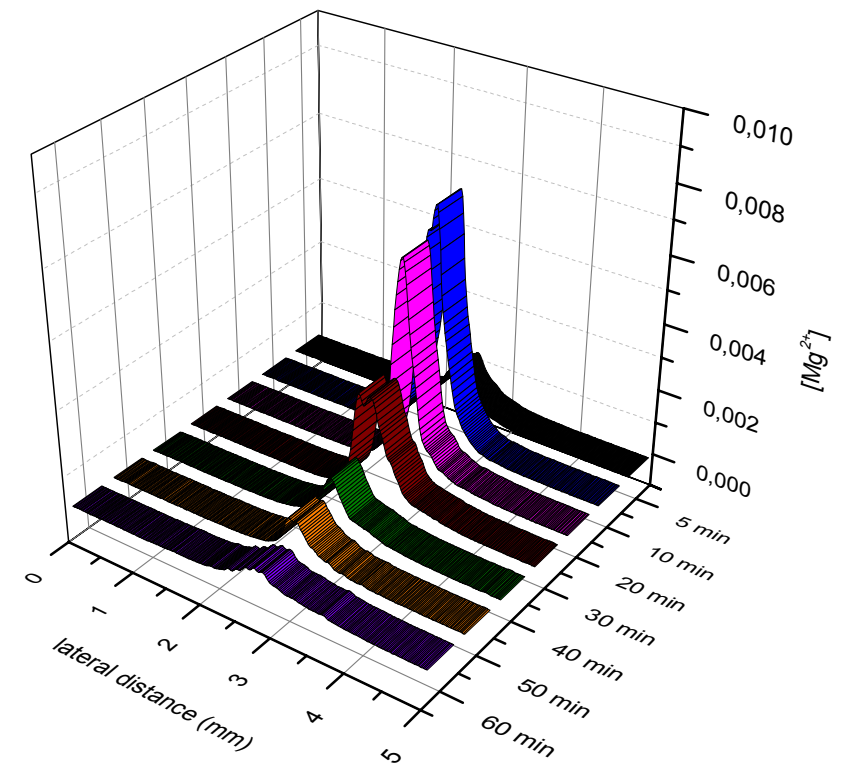

Fig. 5. Concentration-distance lateral scans at $z=100 \mu \mathrm{m}$ height for different instants in time over the corroding $\mathrm{Mg} / \mathrm{Al}$ sample measured with the $\mathrm{Mg}^{2+}$ ISME tip.

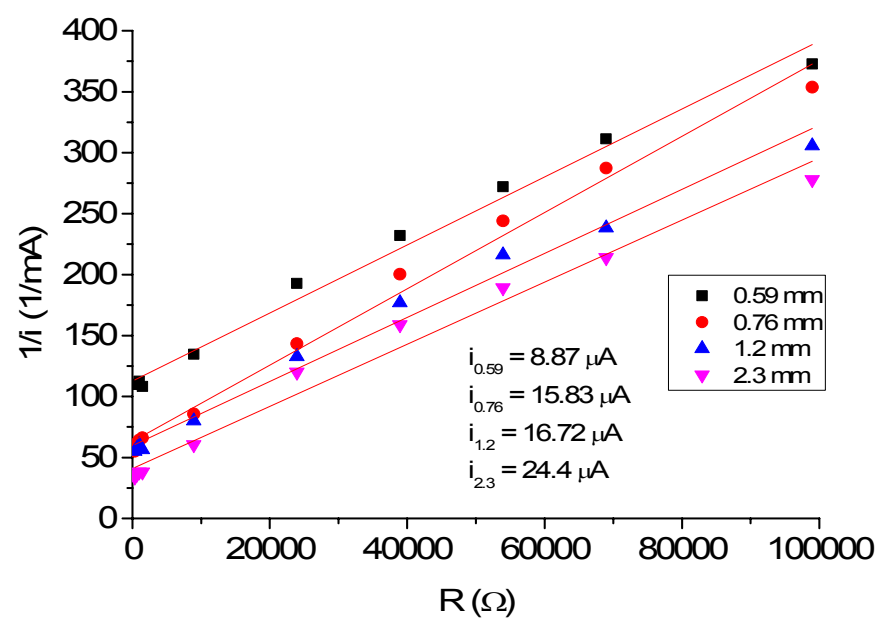

Fig. 6. $1 / i$ plots used for the determination of corrosion current between the $\mathrm{Mg} / \mathrm{Al}$ and various Fe samples of different diameters.

\section{Conclusion}

Most of the SECM studies in the literature have been carried out with amperometric microtips. The applicability of new potentiometric tips has been tested in this work. SECM is a powerful tool in the field of corrosion science. $\mathrm{Mg}^{2+}$ ion-selective electrodes combined with SECM can be used to determine $\mathrm{Mg}^{2+}$ ion concentration distribution in a corroding system, with, and without coupling. Useful information, such as lateral and vertical concentration distribution, can be collected concerning the corrosion of metals. The gathered information can be used to calculate other parameters such as ion flow rates. This new method can be used to study the corrosion of any metal, substituting the tip with the appropriate ion-selective microelectrode. It is expected that the efficiency of corrosion protecting coatings can be tested using SECM with potentiometric tips. 
Fig. 4. Retracting scans above the center of the $\mathrm{Mg} / \mathrm{Al}$ sample. Scans were carried out while the $\mathrm{Mg} / \mathrm{Al}$ and Fe samples were disconnected (left), and also when they were electically coupled (right).

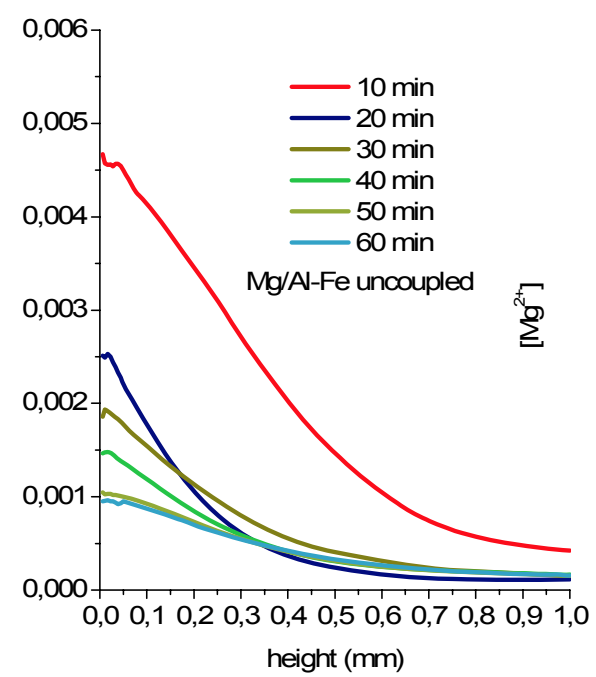

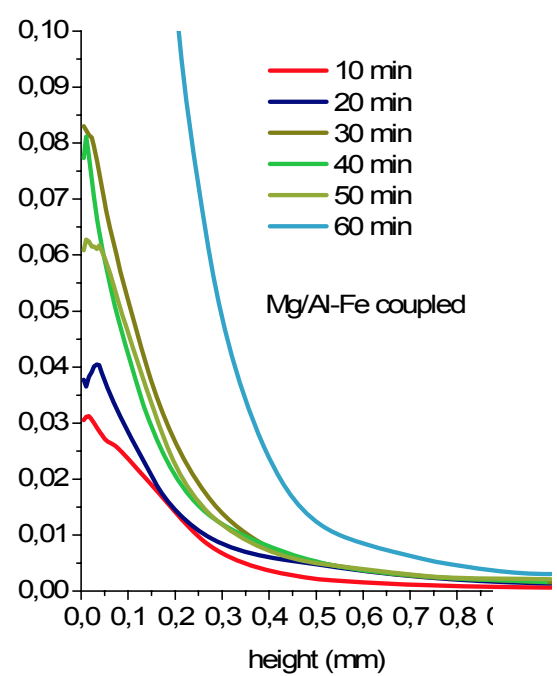

\section{References}

1 González-García Y, Burstein GT, González S, Souto RM, Electrochemistry Communications, 6(7), (2004), 637-642.

2 Souto RM, González-García Y, González S, Corrosion Science, 50(6), (2008), 1637-1643.

3 Gyetvai G, Sundblom S, Nagy L, Ivaska A, Nagy G, Solid contact micropipette ion selective electrode for potentiometric SECM, Electroanalysis, 19, (2007), 1116.

4 Gyetvai G, Nagy L, Ivaska A, Hernádi I, Nagy G, Solid contact micropipette ion selective electrode II: potassium electrode for SECM and in vivo applications, Electroanalysis, 21, (2009), 1970.
5 Csóka B, Kovács B, Nagy G, Investigation of concentration profiles inside operating biocatalytic sensors with scanning electrochemical microscopy (SECM), Biosensors and Bioelectronics, 18(2-3), (2003), 141-149.

6 Bard AJ, Mirkin MV, Scanning Electrochemical Microscopy, Marcel Dekker, Inc., ISBN 0-8247-0471-1.

7 Lide DR(ed.), CRC Handbook of Chemistry and Physics, 85th edn., CRC Press, 2004-2005.

8 Varga Á, Nagy L, Izquierdo J, Bitter I, Souto RM, Nagy G, Development of solid contact micropipette Zn-ion selective electrode for corrosion studies, Analytical Letters, 44, (2011), 2876-2886. 